\title{
Identificação Sorológica de Espécies de Potyvirus em Melancia, no Estado de Roraima
}

\author{
Bernardo A. Halfeld-Vieira ${ }^{1}$, Najara F. Ramos*2, Francisco A.C. Rabelo Filho², M. Fátima B. Gonçalves ${ }^{2}$, \\ Katia L. Nechet ${ }^{1}$, Paulo R.V.S. Pereira ${ }^{1} \&$ J. Albersio A. Lima ${ }^{2 *}$
}

\author{
${ }^{1}$ Embrapa Roraima, Boa Vista, RR, e-mail: halfeld@cpafrr.embrapa.br; ${ }^{2}$ Laboratório de Virologia Vegetal, UFC, \\ CEP 60451-970, Fortaleza, CE, e-mail: albersio@ufc.br
}

(Aceito para publicação em 04/11/2004)

Autor para correspondência: Bernardo A. Halfeld-Vieira

HALFELD-VIEIRA, B.A., RAMOS, N.F., RABELO FILHO, F.A.C., GONÇALVES, M.F.B., NECHET, K.L., PEREIRA, P.R.V.S. \& LIMA, J.A.A. Identificação sorológica de espécies de potyvirus em melancia, no estado de Roraima. Fitopatologia Brasileira 29:687-689. 2004.

\section{RESUMO}

No período de maio de 2003 a março de 2004, foram coletadas amostras foliares de plantas de melancia (Citrullus lanatus) de 21 campos de cultivo de cucurbitáceas, no Estado de Roraima. As amostras exibiam diferentes sintomas de vírus e foram levadas para o Laboratório de Virologia Vegetal da Universidade Federal do Ceará para serem testadas por "enzyme linked immunosorbent assay" (Elisa)indireto, contra anti-soros específicos para Cucumber mosaic virus (CMV), Papaya ringspot virus estirpe melancia (PRSV-W), Watermelon mosaic virus (WMV) e Zucchini yellow mosaic virus (ZYMV). Nos testes de Elisa, utilizou-se o conjugado universal, antiimunoglobulina (IgG) de coelho produzida em cabra conjugada à enzima fosfatase alcalina. Todas as amostras foram testadas, também, por dupla difusão contra o anti-soro para Squash mosaic virus (SqMV).
Os resultados indicaram a presença do PRSV-W em $84,2 \%$ das amostras coletadas em maio de 2003 , em 7,1\% das amostras coletadas em dezembro de 2003 e em 55,6\% das amostras coletadas em março de 2004. A presença do ZYMV foi observada em 10,5\% das amostras coletadas em maio de 2003, 21,4\% das amostras coletadas em dezembro de 2003 e em $25,9 \%$ das amostras de março de 2004 . O WMV foi detectado somente em oito das amostras coletadas em março de $2004(29,6 \%)$. Os resultados desta pesquisa confirmam a ampla dispersão do PRSV-W em cultivos de cucurbitáceas no território brasileiro e a preocupante expansão do ZYMV em razão dos elevados prejuízos que o mesmo tem causado em outras partes do mundo.

Palavras-chave adicionais: incidência de vírus, Citrullus lanatus, WMV, PRSV-W, ZYMV.

\section{ABSTRACT}

Serological identification of virus species in watermelon in the State of Roraima

Leaf samples were collected from watermelon plants (Citrullus lanatus) from 21 different fields in the state of Roraima from May/2003 to March/2004. The samples were sent to the Plant Virus Laboratory of the Federal University of Ceará, to be tested by indirect enzyme linked immunosorbent assay (Elisa) against antisera specific to Cucumber mosaic virus (CMV), Papaya ringspot virus strain watermelon (PRSV-W), Watermelon mosaic virus (WMV) and Zucchini yellow mosaic virus (ZYMV). The Elisa tests were processed using the universal conjugate, antiimunoglobulim (IgG) from rabbit produced in goat, conjugated to alkaline phosphatase. All samples were also tested by double immunodifusion against antiserum specific to Squash mosaic virus (SqMV). The presence of PRSV-W was detected in $84.2 \%$ of the samples collected in May/2003, in $7.1 \%$ of the samples collected in December/2003 and 55,6\% in March/2004. The presence of ZYMV was detected in $10.5 \%$ of the samples collected in May, in $21.4 \%$ in December/2003 and in $25.9 \%$ in March/2004. The WMV was detected only in eight of the samples collected in March/2004 (29.6\%). These results confirm the world widespread dispersion of PRSV-W in cultivated cucurbit fields in Brazil and rise a concern about the ZYMV expansion, which has caused serious yield lost in other parts of the world.
No estado de Roraima, as cucurbitáceas constituem importante fonte de renda para agricultores, sendo a melancia [Citrullus lanatus (Thunb) Matsum \& Nakai] a principal espécie cultivada. Os maiores produtores estão localizados na região nordeste do estado, nos municípios de Normandia e Bonfim, que comercializam os produtos principalmente para Manaus-AM e Boa Vista-RR. No sul do estado predominam pequenos produtores que praticam cultivo de subsistência ou visam o abastecimento do mercado local. O cultivo é limitado por doenças, sendo aquelas ocasionadas por vírus, as que

$\overline{\text { *Bolsistas do } \mathrm{CNPq}}$ ocorrem em percentuais elevados, causando prejuízos em produção, em conseqüência das reduções na quantidade e qualidade dos frutos.

No Brasil, em geral, os vírus da família Potyviridae são os que têm recebido maior atenção por representarem fatores limitantes no cultivo de melancia e de várias outras cucurbitáceas nas principais regiões produtoras do país. O gênero Potyvirus se sobressai em importância econômica para as cucurbitáceas, por conter três espécies de relevância para os cultivos do meloeiro (Cucumis melo L.) e da melancia: vírus da mancha anelar do mamoeiro estirpe melancia (Papaya ringspot virus strain watermelon, PRSV-W), vírus 


\section{B.A. Halfeld-Vieira et al.}

do mosaico da melancia (Watermelon mosaic virus, WMV) e vírus do mosaico amarelo do zucchini (Zucchini yellow mosaic virus, ZYMV). A patologia destas três espécies de vírus pode ser observada por uma série de sintomas, que incluem mosqueado, mosaico, clorose, necrose, deformação foliar e de frutos, e até mesmo infecção latente, sem sintomas macroscópicos (Oliveira et. al., 2000). Outro vírus de importância econômica para as cucurbitáceas é o vírus do mosaico do pepino (Cucumber mosaic virus, CMV) família Bromoviridae, gênero Cucumovirus. Dentre as espécies que constituem o genêro Cucumovirus, o CMV, além de apresentar a maior gama de hospedeiros conhecida, pode interagir sinergisticamente com vírus do gênero Potyvirus, intensificando os sintomas da infecção (Ramos et al., 2003). A sintomatologia descrita para o CMV varia de mosaico comum a sintomas bem severos, podendo levar a planta à morte.

O presente trabalho teve como objetivo a identificação sorológica e distribuição dos vírus que estão infetando os campos experimentais e de produção de melancia no Estado de Roraima.

\section{Coleta de amostras foliares de plantas exibindo sintomas de vírus}

Foram realizadas coletas de amostras foliares de plantas de melancia exibindo diferentes sintomas de vírus, em 21 campos representativos de cultivo de cucurbitáceas no período de maio de 2003 a março de 2004, nos municípios de Boa Vista, Bonfim, Caroebe, Cantá, Normandia e Rorainópolis. Os locais de coleta foram georeferenciados com o uso de Garmin e Trex ${ }^{\circledR}$ Legend (GPS) para confecção do mapa (Figura 1). As amostras foram acondicionadas em sacos

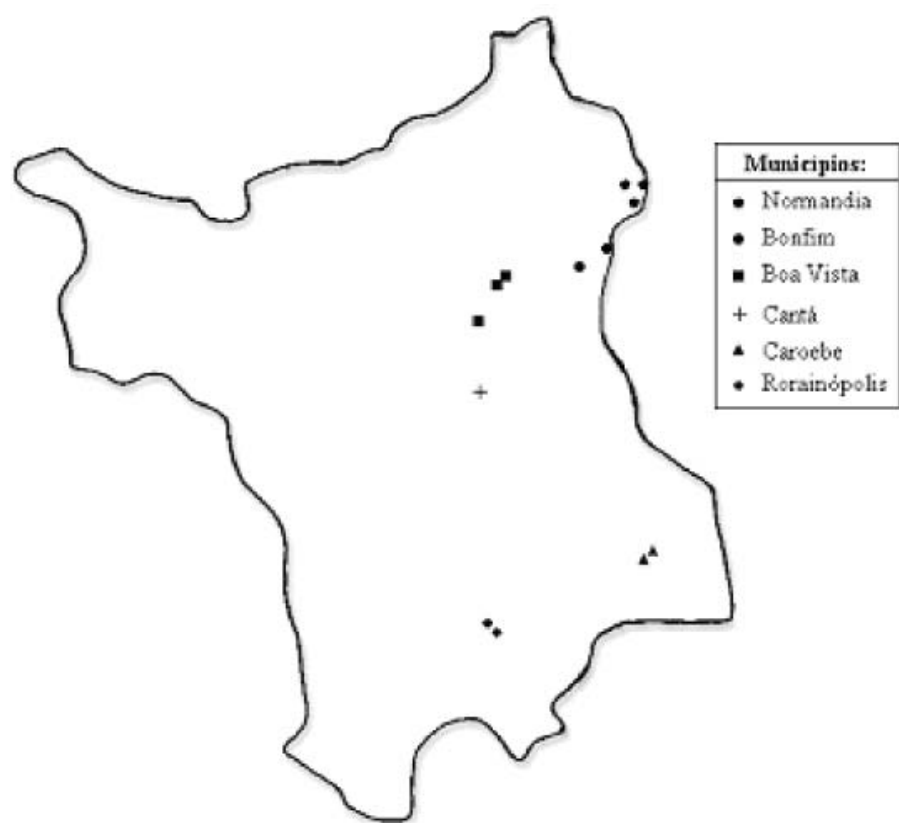

FIG. 1 - Mapa do Estado de Roraima indicando os locais de coleta de melancia (Citrullus lanatus) em lavouras representativas de diferentes municípios, georeferenciados com o uso de Garmin e Trex ${ }^{\circledR}$ Legend (GPS). Lavouras próximas estão representadas por um único ponto. plásticos e mantidas em refrigeração até o momento do envio para análise sorológica que foi realizada no Laboratório de Virologia Vegetal da Universidade Federal do Ceará (UFC). As amostras foram testadas por "enzyme linked immunosorbent assay" (Elisa) indireto, contra anti-soros específicos para CMV, PRSV-W, WMV e ZYMV, usando o conjugado universal, anti-imunoglobulina ( $\mathrm{IgG}$ ) de coelho produzida em cabra conjugada à enzima fosfatase alcalina (Almeida, 2001). De acordo com o critério adotado para as análises, foram consideradas positivas as leituras que correspondiam ao triplo dos valores de absorbância registrados para os extratos de plantas sadias, usadas como testemunhas.

Todas as amostras foram testadas, também, por dupla difusão em Agar contra o anti-soro para o vírus do mosaico da abóbora (Squash mosaic virus, SqMV), família Comoviridae, gênero Comovirus. Em todos os testes, incluíram-se como controle, extratos de plantas sadias e o antígeno homólogo de SqMV. As placas foram mantidas em câmara úmida à temperatura de $37{ }^{\circ} \mathrm{C}$ por $12 \mathrm{a} 18 \mathrm{~h}$ em incubadora BOD e observadas quanto a presença de faixas de precipitação resultantes das combinações específicas entre antígeno e anticorpo.

Os resultados indicaram a presença de PRSV-W, WMV e ZYMV em infecções simples e mista. A presença do PRSV$\mathrm{W}$ foi constatada em $84,2 \%$ das amostras de melancia coletadas em maio de 2003, sendo encontrada uma única planta infetada com esse vírus em dezembro de 2003 (Tabela 1). Nas plantas coletadas em março de 2004, 55,6\% das amostras estavam infetadas com PRSV-W, sendo que 3,3\% estavam com infecção mista, envolvendo WMV (2\%) e ZYMV $(1,3 \%)$. Foram, também, constatados quatro casos com infecção tripla, estando as amostras com PRSV-W, WMV e ZYMV. O ZYMV foi detectado em 10,5\% das plantas coletadas em maio/03, em 21,4\% das amostras coletadas em dezembro/03 e em $25,9 \%$ das amostras coletadas em março de 2004 (Tabela 1). Todas as amostras positivas para WMV apresentaram infecção mista. A sintomatologia das plantas infetadas com PRSV-W se diferenciava daquela apresentada pelas plantas infetadas pelo ZYMV. O PRSV-W encontra-se distribuído mundialmente e é de grande importância

TABELA 1 - Avaliação da presença de vírus em amostras foliares de plantas de melancia (Citrullus lanatus) exibindo diferentes sintomas de vírus, em 21 campos representativos de cultivo de cucurbitáceas no período de maio de 2003 a março de 2004, no Estado de Roraima, detectado por ELISA

\begin{tabular}{lccccc}
\hline \multirow{2}{*}{ Data da coleta } & \multirow{2}{*}{$\begin{array}{c}\text { No. de plantas } \\
\text { testadas }\end{array}$} & \multicolumn{4}{c}{ Número de amostras positivas em Elisa } \\
\cline { 3 - 6 } & & PRSV-W & WMV & ZYMV & Sem Infecção \\
\hline Maio/2003 & 19 & $16(84,2)^{2}$ & $0-$ & $2(10,5)$ & $1(5,3)$ \\
Dezembro/2003 & 14 & $1(7,1)$ & $0-$ & $3(21,4)$ & $10(71,4)$ \\
Marco/2004 & 27 & $15(55,6)$ & $8(29,6)$ & $7(25,9)$ & $12(44,4)$ \\
Total & $\mathbf{7 2}$ & $\mathbf{3 2}(\mathbf{4 4 , 4 )}$ & $\mathbf{8 ( 1 1 , 1 )}$ & $\mathbf{1 2}(\mathbf{1 6 , 7 )}$ & $\mathbf{3 5 ( 4 8 , 6 )}$ \\
\hline
\end{tabular}

${ }^{1}$ Valores de Elisa $\left(\mathrm{A}_{405}\right)$ foram considerados positivos quando superiores a $3 \mathrm{x}$ a média dos controles negativos na respectiva microplaca

${ }^{2}$ Percentagens de infecção 
Identificação sorológica e distribuição de espécies de potyvirus ...

econômica onde as cucurbitáceas são cultivadas (Purcifull et al., 1984a). As perdas na produção e os graus de incidência já foram estimados em várias regiões, inclusive no Nordeste brasileiro (Nelson et al., 1962; Oliveira et. al., 2000; Ramos et al., 2003). Além disso, essa virose pode ser considerada limitante à produção de diversas cucurbitáceas, principalmente quando a infecção ocorre no início do ciclo. No Brasil, grande atenção tem sido dada ao PRSV-W, por ser o vírus de maior abrangência geográfica detectado em cucurbitáceas. O mesmo já foi identificado em vários estados, causando grandes prejuízos à produção de diversas espécies de cucurbitáceas (Lima et al., 1980; Pavan et al., 1989; Oliveira et. al., 2000). O PRSV-W também é de ocorrência predominante em regiões produtoras de melão de Belém (Albuquerque et. al., 1972) e de abóbora (Cucurbita moschata Duch.) e meloeiro no Ceará (Lima \& Vieira, 1992; Oliveira et. al., 2000).

O primeiro registro da ocorrência do ZYMV na América do Sul foi em 1992 no estado de São Paulo e Santa Catarina (Vega et al., 1992; Canner et al., 1992). Em 1996, o vírus foi constatado causando sérios problemas em abóbora, em Salta, na Argentina (Gracia, 2000). Em seguida, o ZYMV foi identificado nos estados do Rio Grande do Norte (Lima et al., 1996) e do Ceará (Lima et al., 1997). A identificação do ZYMV no Nordeste brasileiro (Lima et. al., 1996) e sua expansão constatada por Oliveira et. al. (2000) é motivo de preocupação para produtores, em razão de elevados prejuízos em várias outras partes do mundo (Purcifull et. al., 1984b).

Nenhuma das amostras testadas reagiu com o antisoro para CMV e SqMV. Estes resultados demonstram a possível ausência do SqMV na região ou a inexistência de estirpe capaz de infetar a melancia, cultura, predominantemente, analisada nessa pesquisa.

Este constitui o primeiro relato sobre a presença do PRSV-W e do ZYMV em melancia no estado de Roraima, revelando a necessidade de estudos detalhados sobre os graus de incidência de vírus em cucurbitáceas na região e avaliação do comportamento de genótipos a serem cultivados.

Os resultados desta pesquisa confirmam a ampla dispersão do PRSV-W em cultivos de cucurbitáceas no território brasileiro e a previsão de Lima et al. (1996) sobre a preocupante expansão do ZYMV no Brasil a semelhança do que tem ocorrido em nível mundial (Lisa \& Lecoq, 1984; Lecoq et al., 1991).

\section{REFERÊNCIAS BIBLIOGRÁFICAS}

ALBUQUERQUE, F.C., IKEDA, H. \& COSTA, A.S. Ocorrência do vírus do mosaico da melancia (Citrullus vulgaris Schrad.) em plantações de melão (Cucumis melo L.) na região de BelémPA. Revista de Olericultura 12:94. 1972. (Resumo)

ALMEIDA, A.M.R. Detecção e quantificação de vírus pelo teste ELISA. In: Almeida, A.M.R. \& Lima, J.A.A. (Eds.) Princípios e técnicas aplicados em fitovirologia. Fortaleza. Fitopatologia
Brasileira. 2001. pp.63-94.

CANNER, J., GALLETI, S.R., LOTZ, I.P.M. \& OLIVEIRA, J.M. Natural infection of cucumber (C. sativus) by Zucchini yellow mosaic virus in Santa Catarina, Brazil. In: Encontro Nacional de Virologia, São Lourenço, MG. 1992. (Resumo).

GRACIA, O. First report of Zucchini yellow mosaic virus in Argentina. Plant Disease 84:371. 2000.

LECOQ, H., LEMAIRE, J.M. \& WIPF-SCHEIBEL, C. Control of zucchini yellow mosaic virus in squash by cross protection. Plant Disease 75:208-211. 1991.

LIMA, J.A.A. \& VIEIRA, A.C. Distribuição do vírus do mosaico da abóbora em municípios cearenses e gama de hospedeiros de um isolado. Fitopatologia Brasileira 17:112-114. 1992.

LIMA, J.A.A., FERNANDES, E.R. \& MENDES, M.L. Identificação sorológica de "Watermelon mosaic virus 1 " em cucurbitáceas cultivadas e nativas do Rio Grande do Norte. Fitopatologia Brasileira 5:414. 1980. (Resumo).

LIMA, J.A.A., VALE, C.C. \& OLIVEIRA, V.B. Viruses that infect cucurbits in the northeast of Brazil. Virus: Reviews and Research 2:128-130. 1997.

LIMA, J.A.A., VALE, C.C., MIRANDA, A.C.M.M. \& OLIVEIRA, V.B. Identificação sorologica do "Zucchini yellow mosaic virus" em plantios de melão no Rio Grande do Norte. Fitopatologia Brasileira 21:426. 1996. (Resumo).

LISA, V. \& LECOQ, H. Zucchini yellow mosaic virus. Kew:CMIAAB, Descriptions of plant viruses, No 282. 1984.

NELSON, M.R., ALLEN, R.M. \& TUTTLE, D.M. Distribution, prevalence and importance of some cantaloup virus disease in Southwestern Arizona. Plant Disease Reporter 46:667-672. 1962.

OLIVEIRA, V.B., LIMA, J.A.A., VALE, C.C. \& PAIVA, W.O. Caracterização biológica e sorológica de isolados de potyvirus obtidos de cucurbitáceas no Nordeste brasileiro. Fiopatologia Brasileira 25:628-636. 2000.

PAVAN, M.A., CARVALHO, M.G. \& FERnANDES, J.J. Distribuição do vírus do mosaico da melancia (Papaya ringspot virus-w), nas principais regiões produtoras de pepino (Cucumis sativus) e abobrinha (Cucurbita pepo) e Minas Gerais. Fitopatologia Brasileira 14:84-85. 1989.

PURCIFULL, D.E., EDWARDSON, J.R., HIEBERT, E. \& GONSALVES, D. Papaya ringspot virus (revised) No 292 In: Descriptions of plant viruses. CMI/AAB, Kew, Surrey, England. 1984a.

PURCIFULL, D.E., ALDERZ, W.C., SIMONE, G.W., HIEBERT, E. \& CHRISTIE, S.R. Serological relationships and partial characterization of zucchini yellow mosaic virus isolated from squash in Florida. Plant Disease 68:230-233. 1984 b.

RAMOS, N.F., LIMA, J.A.A. \& GONÇALVES, M.F.B. Efeitos da interação de potyvirus em híbridos de meloeiro, variedades de melancia e abobrinha. Fitopatologia Brasileira 28:1999-203. 2003.

VEGA, J. REZENDE, J.A.M., YUKI, V.A. \& NAGAI, H. Constatação do vírus do mosaico amarelo da abobrinha-de-moita ("Zucchini yellow mosaic virus") no Brasil através de MEIADE e ELISA. Fitopatologia Brasileira 17:188. 1992. (Resumo). 